\title{
Tribological Behavior of Phenolic Resin-Based Friction Composites Filled with Graphite
}

\author{
En Zhang (D), Fei Gao *, Rong Fu, Yunzhuo Lu, Xiaoming Han and Linlin Su
}

\author{
School of Materials Science and Engineering, Dalian Jiaotong University, Dalian 116028, China; \\ enn@djtu.edu.cn (E.Z.); furong@djtu.edu.cn (R.F.); yunzhuohit@gmail.com (Y.L.); hanxm@djtu.edu.cn (X.H.); \\ sulinlin90@163.com (L.S.) \\ * Correspondence: gaofei@djtu.edu.cn; Tel.: +86-0411-8410-9425
}

Citation: Zhang, E.; Gao, F.; Fu, R.; Lu, Y.; Han, X.; Su, L. Tribological Behavior of Phenolic Resin-Based Friction Composites Filled with Graphite. Materials 2021, 14, 742. https://doi.org/10.3390/ ma14040742

Academic Editor: Pawel Pawlus Received: 10 January 2021

Accepted: 1 February 2021

Published: 5 February 2021

Publisher's Note: MDPI stays neutral with regard to jurisdictional claims in published maps and institutional affiliations.

Copyright: (c) 2021 by the authors. Licensee MDPI, Basel, Switzerland. This article is an open access article distributed under the terms and conditions of the Creative Commons Attribution (CC BY) license (https:// creativecommons.org/licenses/by/ $4.0 /)$.

\begin{abstract}
In this paper, the influence of graphite (Gr) on the dry sliding tribological properties of phenolic resin (PF) composites was studied under different sliding speeds of 3.1-47.1 m/s. The wear mechanism was investigated by the observation of the morphology of the transfer layer during the dry sliding process. It was found that the addition of $\mathrm{Gr}$ could decrease the friction coefficient and wear rate effectively, and the friction coefficient and wear rate decreased with the increase of Gr content in the range of 10-30 vol.\%. The dominant wear mechanisms of PF-based friction composites changed from adhesive wear to fatigue wear (in the form of peeling-off) in the high sliding speed condition after the addition of Gr. The addition of Gr effectively reduced the sensitivity of PF-based friction materials to sliding speeds, and thus enhanced the stability of the friction coefficient. When the content of Gr was above 20 vol. $\%$, the stability of the friction coefficient was relatively steady.
\end{abstract}

Keywords: polymer-matrix composite; graphite; mechanism; solid lubricants

\section{Introduction}

The development of high-speed trains necessitates higher requirements to the brake system. The tribological properties and compositions of friction materials directly affect safe and comfortable brake performance and the ecological environment [1-11]. In recent years, the disc brake system is the most widely used on high-speed trains. The organic brake pads, due to their lighter weight, fewer pollutants and lower energy consumption, have important research value in the development of high-speed train brake systems.

Among organic materials, phenolic resin (PF) with low density, high bonding strength with fillers, good environmental performance and high reliability under severe conditions, has been widely used in braking materials for $250 \mathrm{~km} / \mathrm{h}$ trains, heavy-duty vehicles and cars etc., and numerous applications [12-19]. It has become one of the important organic brake materials [20-27]. However, with the condition of sliding against the steel braking disc, according to Archard's friction theory [28] that the removal of lumps from contact areas formed by plastic deformation, high adhesion occurs on the PF. Therefore, the PF shows high wear rate and a large fluctuating friction coefficient, which should be used coupled with the solid lubricant for stable tribological performances [23,29-31].

Graphite (Gr), due to its lamellar structure, is an essential solid lubricant component. $\mathrm{Gr}$ is found to decrease the friction coefficients and wear rates of resin-based friction materials effectively [1,32-40]. For instance, Cho et al. [41] investigated the tribological properties of solid lubricants for automotive brake friction materials. They found that the PF-based friction materials containing $\mathrm{Sb}_{2} \mathrm{~S}_{3}$ and $\mathrm{Gr}$ improved the friction stability and fade resistance. Zhu et al. [40] reported the friction and wear behavior of furan resin-Gr composite under dry sliding. The results showed that the interaction of furan resin and wear debris of graphite was useful to reduce the wear rate of furan resin-Gr composite. Alajmi et al. [42] investigated the correlation between mechanical properties with specific wear rate and the coefficient of friction of Gr-epoxy composites. They concluded that 
graphite led to eclectic effects on mechanical properties of graphite/epoxy composites at the same time as affirmative effects on tribological properties of graphite/epoxy composites.

Recent investigations mainly focus on the influence of surface morphology variation on the tribological properties of resin-based multi-component friction materials under different pressures and sliding speeds. The tribological properties of friction material are directly affected by the formation process and composition of transfer layers generated during the sliding contact. With the fillers like glass fibers, aramid pulp, $\mathrm{Sb}_{2} \mathrm{~S}_{3}, \mathrm{MoS}_{2}$ and other components, the study of the transfer layer formation and wear mechanism of Gr in a PF-matrix becomes extremely arduous because of the variation of the transfer layer composition and the interaction between fillers. So far, the effect of Gr on the formation of the transfer layer and wear mechanism is still elusive.

In the present study, we carried out an experiment on the pin-on-disc configurations in a wear-testing machine with a H13 disc sliding against the PF composites. The investigation was on the tribological properties and friction morphology of a series of Gr-PF composites with $\mathrm{Gr}$ content in the range of 0-30 vol.\% under the different sliding speeds of 3.1-47.1 m/s. The study aims to identify the effect of $\mathrm{Gr}$ on the formation of a lubricating layer of Gr-PF composite in the dry sliding process, consequently revealing the wear mechanisms.

\section{Experimental Procedure}

\subsection{Sample Preparation}

The Gr-PF composites were packed in a mold with Gr granules and PF powders. The PF powders containing hexamethylenetetraminse (a curing agent) were used as the matrix. Gr granules with an average size of $300 \mu \mathrm{m}$ were added to the PF powders at the volume fractions of 0 vol.\%, 10 vol.\%, 20 vol.\%, 25 vol.\% and 30 vol.\% (denoted as 0Gr, 10Gr, 20Gr, $25 \mathrm{Gr}$, and 30Gr) each as shown in Table 1. Five samples for each volume fraction set were prepared. The ingredients were mixed in a rotary mixer for 1-2 min until they were even, and then kept static for 5-10 min in order to prevent them from wafting out. The mixed raw material powders were loaded into a $\Phi 25 \mathrm{~mm} \times 80 \mathrm{~mm}$ mold and hot pressed at $180{ }^{\circ} \mathrm{C}$ and $0.23 \mathrm{MPa}$ for $50 \mathrm{~min}$ in an oven. After releasing the pressure and taking the specimen out of the mold, they were put into an oven and post-cured at $180^{\circ} \mathrm{C}$ for $5 \mathrm{~h}$.

Table 1. The composition of friction materials in the volume fraction.

\begin{tabular}{ccc}
\hline Specimens & PF (vol.\%) & Gr (vol.\%) \\
\hline $0 \mathrm{Gr}$ & 100 & 0 \\
$10 \mathrm{Gr}$ & 90 & 10 \\
$20 \mathrm{Gr}$ & 80 & 20 \\
$25 \mathrm{Gr}$ & 75 & 25 \\
$30 \mathrm{Gr}$ & 70 & 30 \\
\hline
\end{tabular}

\subsection{Measurements}

The tribological properties of the PF-based friction composites were investigated under dry sliding conditions with pin-on-disc configurations in a wear-testing machine. The friction force generated during the friction test was transformed into the pull force of the sensor, which could show the change curve of the friction coefficient with the friction time on the computer, and the average value of the friction coefficient in the test time was also given. The pin (specimen) was $\Phi 25 \mathrm{~mm} \times 15 \mathrm{~mm}$. A steel disc made of H13 steel of $308 \mathrm{HB}$ was used as the counterpart and the turning radius was $150 \mathrm{~mm}$. At the beginning of the test, the cured pin specimen was pre-ground until it achieved a complete contact with the disc on pin-on-disc tribometer. The surface roughness ( $\mathrm{Ra}$ ) of the pin was 3-6 $\mu \mathrm{m}$. The contact surface of the disc was polished by hand with grand $800-$ and 2000-grit abrasive papers, respectively, cleaned with acetone to remove the surface contaminants and dried prior to testing. The contact surface roughness $(\mathrm{Ra})$ of the steel disc was $<1.5 \mu \mathrm{m}$. The ranges of the sliding speeds were $3.1-47.1 \mathrm{~m} / \mathrm{s}$ with the contact pressure of $0.51 \mathrm{MPa}$. The testing experiments were carried out for $5 \mathrm{~min}$ for each friction (the ranges of sliding 
distance are $930-14,130 \mathrm{~m})$. The friction stability was defined as $\mu_{\mathrm{avg}} / \mu_{\max } \times 100 \%$, where $\mu_{\text {avg }}$ was the mean of dynamic friction coefficient $\left(\mu_{\mathrm{d}}\right)$, and $\mu_{\max }$ was the maximum of $\mu_{\mathrm{d}}$ [43]. Wear rate was measured as a weight loss method followed by conversion in volume loss using density data. The wear rate is expressed in the form of specific wear rate, $\mathrm{K}\left(\mathrm{m}^{3} / \mathrm{Nm}\right)$ and calculated as,

$$
\mathrm{K}=\Delta \mathrm{m} / \mathrm{ut} \rho \mathrm{P}
$$

where $\Delta \mathrm{m}$ is weight loss in $\mathrm{g}, \mathrm{u}$ is sliding speed in $\mathrm{m} / \mathrm{s}, \mathrm{t}$ is sliding time in $\mathrm{s}, \rho$ is density in $\mathrm{g} / \mathrm{m}^{3}$ and $\mathrm{P}$ is load in Newton.

The microstructures of the friction surfaces were observed by an optical metallographic microscope (OM), confocal scanning laser microscope and scanning electron microscope (SEM). The parameter statistic of grooves on the worn surface was measured by a confocal scanning laser microscope. The worn surface was investigated with SEM after gold coating and operated at $20 \mathrm{kV}$.

\section{Results and Discussion}

\subsection{Material Features}

Figure $1 \mathrm{a}$ is the morphology of the raw matrix of PF before test. As can be seen, the surface is dense with few micro-fissures. The micro-fissures are also present in other four specimens compounded with Gr. The micro-fissures may be caused by the volume change during the post-cure processing. It can also be found from Figure 1a that the Gr granules, at the size of 300 to $400 \mu \mathrm{m}$, are randomly distributed in the matrix. In addition, as shown in Figure $1 \mathrm{~b}-\mathrm{e}$, the cross-section area of Gr granules increases with the increasing Gr content (shows in Figure 1f). It can also be noted from Figure 1d,e that gaps appear between the matrix and Gr granules in specimens with higher Gr content. In contrast, the matrix is tightly bound to Gr granules in the specimens with lower Gr content, as presented in Figure $1 b, c$. The formation of the gaps between matrix and Gr granules is due to the poor interfacial bonding of matrix and Gr granules [44,45].

\subsection{Friction and Wear Properties}

Figure 2 shows the variations of the friction coefficients and wear rates of the PF-based friction composites filled with different contents of Gr, sliding against the steel disc at an increasing sliding speed. The on-line friction curves of each PF composite are shown in Appendix A Figure A1. The data for the raw matrix of PF are also presented in Figure 2 for comparison. By contrast with the other four kinds of composite, the PF is sensitive to the speeds and the variations of the friction coefficient. That is, the PF shows a friction coefficient of 0.28 at $7.9 \mathrm{~m} / \mathrm{s}$, and then decreases with the increase of speed and obtains the lowest friction coefficient of 0.18 at $15.7 \mathrm{~m} / \mathrm{s}$. The friction coefficient suddenly jumps to 0.41 at $23.6 \mathrm{~m} / \mathrm{s}$ and decreases to 0.37 at $31.4 \mathrm{~m} / \mathrm{s}$. After that, the PF shows a positive friction-rotational speed relationship. The wear rate of PF increases smoothly with the increasing speed from $7.9 \mathrm{~m} / \mathrm{s}$ to $39.3 \mathrm{~m} / \mathrm{s}$. However, when the speed is up to $47.1 \mathrm{~m} / \mathrm{s}$, the wear rate increases sharply, and is more than twice the average wear rate of PF at different speeds (shown in Figure 2a,b). The fluctuant variations of the curves indicates that the friction performance of raw matrix of PF is unstable with the increasing sliding speeds. Frictional phenomena such as severe noise and vibrations are observed during the friction tests, which correspond to PF composite without friction modifier that have been reported [46].

By contrast with unfilled PF, the PF-based composites with the addition of Gr (specimens $10 \mathrm{Gr}, 20 \mathrm{Gr}, 25 \mathrm{Gr}$ and $30 \mathrm{Gr}$ ) show a stable friction-rotational speed relationship. The wear rates of specimens with higher $\mathrm{Gr}$ content $(25 \mathrm{Gr}$ and $30 \mathrm{Gr}$ ) decrease significantly compared to the PF without solid lubricant fillers. In particular, the specimen 10Gr records a stable decreasing friction coefficient and wear rate when the speed reaches $15.7 \mathrm{~m} / \mathrm{s}$. With the speed increasing from 15.7 to $47.1 \mathrm{~m} / \mathrm{s}$, the friction coefficient demonstrates fluctuation at $23.6 \mathrm{~m} / \mathrm{s}$, and then increases smoothly with the speed. Meanwhile, the wear rate increases steadily during the speed from 15.7 to $39.3 \mathrm{~m} / \mathrm{s}$, and then increases sharply when 
the speed rises to $47.1 \mathrm{~m} / \mathrm{s}$ like PF (shows in Figure 2b). This phenomenon is consistent with that of some relevant and recent reported papers, in which the friction coefficient and wear rate decreased with the increasing Gr content below 10 vol.\% [46-48]. The specimen $20 \mathrm{Gr}$ has the same friction coefficient of 0.35 from the speed of 7.9 to $15.7 \mathrm{~m} / \mathrm{s}$. The friction coefficient increases with the increasing speed from 15.7 to $31.4 \mathrm{~m} / \mathrm{s}$, and then reaches stable data between $0.4-0.41$ when the speeds exceed $31.4 \mathrm{~m} / \mathrm{s}$. The variation of the wear rate curve of specimen $20 \mathrm{Gr}$ is similar to that of $10 \mathrm{Gr}$ when the speed rises from 7.9 to $39.3 \mathrm{~m} / \mathrm{s}$. As the speed reaches $47.1 \mathrm{~m} / \mathrm{s}$, the wear rate increases but not so sharply as that of $10 \mathrm{Gr}$. It can be concluded that the specimen $20 \mathrm{Gr}$ has lower friction coefficient and shows better wear resistance compared with specimen 10Gr. The variation of the friction coefficient curve of the specimen $25 \mathrm{Gr}$ is similar to that of $20 \mathrm{Gr}$ but with a lower friction coefficient and the wear resistant. However, $25 \mathrm{Gr}$ is better and more stable than the latter. From Figure 2a,b, the friction coefficient and wear rate of the specimen $30 \mathrm{Gr}$ are much lower than that of other specimens, and show a minor sensitivity both in friction coefficient and wear rate to the rotational speed within the whole range. In general, with the increase of volume fraction of $\mathrm{Gr}$, the frictional composites show lower friction coefficient and better wear resistance with increasing speed.
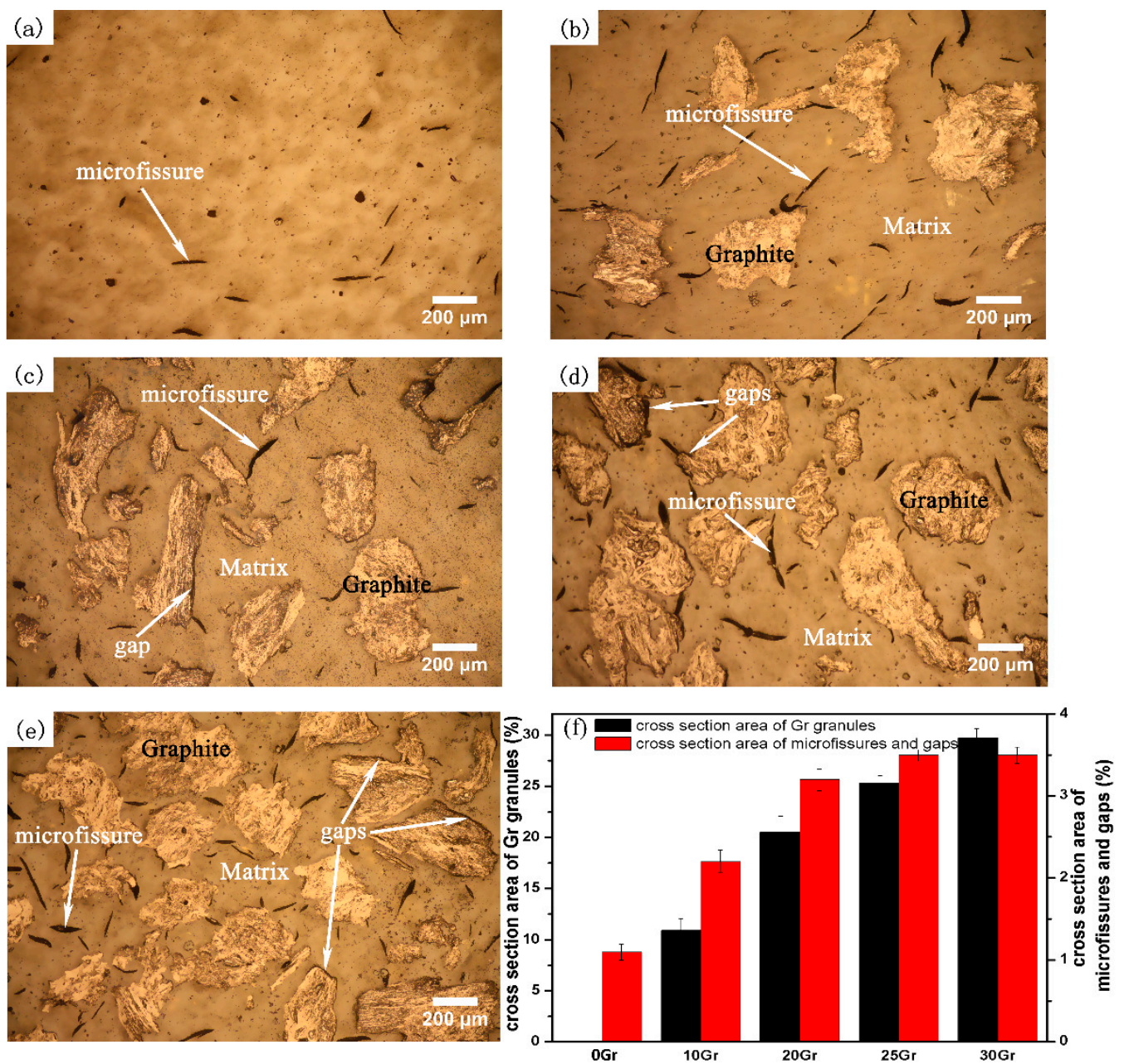

Figure 1. Microstructures of investigated specimens before test: (a) graphite (Gr)-free phenolic resin (PF) matrix; (b) 10 vol.\% Gr/PF; (c) 20 vol.\% Gr/PF; (d) 25 vol.\% Gr/PF; (e) 30 vol.\% Gr/PF, (f) column diagram of $\mathrm{Gr}$ granules, micro-fissures and gaps' cross section area. 

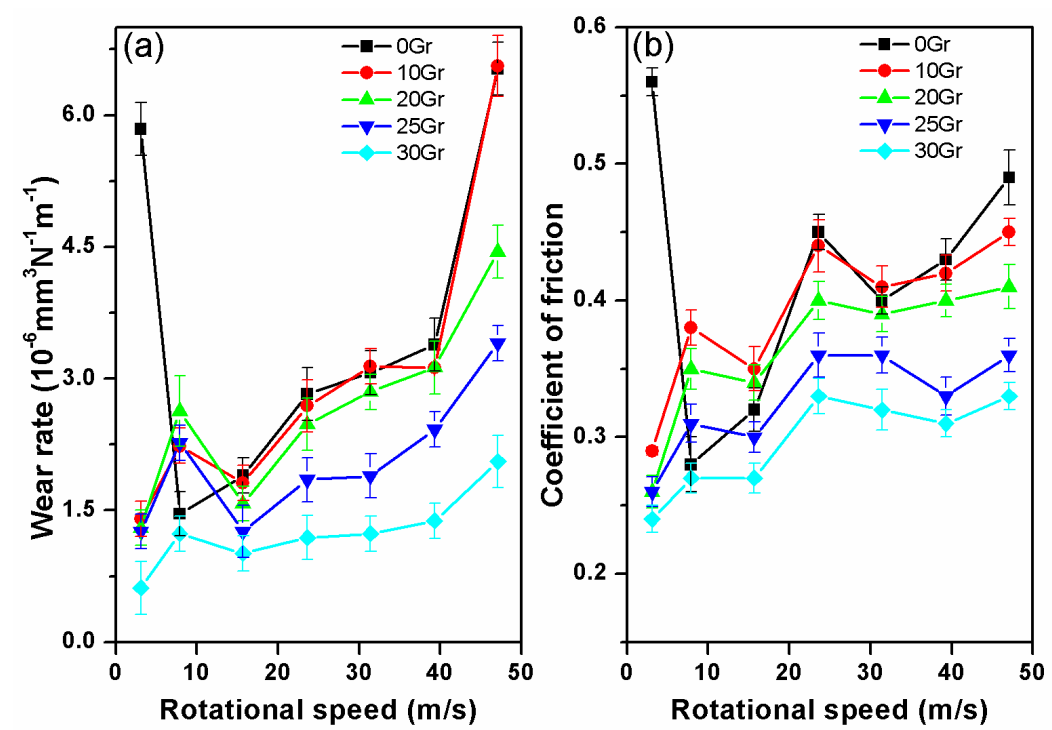

Figure 2. Variations of friction coefficient (a) and wear rate (b) of the PF-based friction composites with an increase in sliding speed at $0.51 \mathrm{MPa}$ for $5 \mathrm{~min}$.

The tribological characteristics of PF-based friction composites are further analyzed in terms of the percentage of friction stability against increasing speed. According to the friction stability equation $\mu_{\mathrm{avg}} / \mu_{\max } \times 100 \%$, taking the friction stability of $10 \mathrm{Gr}$ at $47.1 \mathrm{~m} / \mathrm{s}$ for example, the on-line friction curve of $10 \mathrm{Gr}$ at $47.1 \mathrm{~m} / \mathrm{s}$ is shown in Figure 3a, and the friction stability value of $10 \mathrm{Gr}$ at $47.1 \mathrm{~m} / \mathrm{s}$ is $79 \%$. The friction stability of PF-based composites at different sliding speeds is calculated in this way. The results are shown in Figure $3 \mathrm{~b}$. The undulating range of the friction stability curve shows the sensitivity of PF-based composites to the increasing speed. In other words, if the curve of a friction composite is flat, the friction stability is rated as low sensitivity to speed [44]. As seen from Figure 3b, the friction stability of PF-based composites filled with $\mathrm{Gr}$ is in the range of $79-90 \%$. Meanwhile, the Gr-free PF is in the range of $63-73 \%$ and shows unstable friction performance on wear coefficient. The specimens $20 \mathrm{Gr}, 25 \mathrm{Gr}$ and $30 \mathrm{Gr}$ with higher content of Gr above 20 vol. \% have similar friction stability. However, the specimen $10 \mathrm{Gr}$ shows lower friction stability than others. Each of the differences between maximum and minimum friction stability of the Gr-PF composites (10Gr, 20Gr, 25Gr and 30Gr) is in the narrow range of $5-7 \%$ and shows low sensitivity to speed.
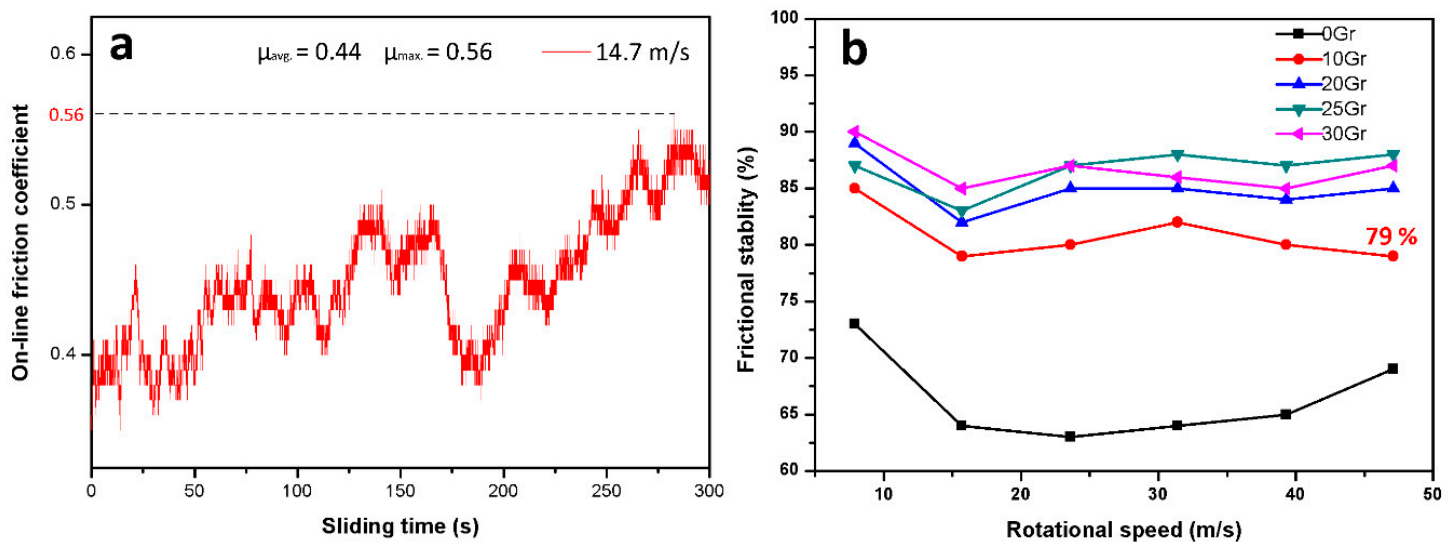

Figure 3. Friction stability of the PF-based friction composites at $0.51 \mathrm{MPa}$ for $5 \mathrm{~min}$ : (a) the on-line friction curve of $10 \mathrm{Gr}$ at $47.1 \mathrm{~m} / \mathrm{s}$; (b) variations of friction stability of the PF-based friction composites with an increase in rotational speed. 
According to Archard's theory of adhesive wear, it can be inferred that the raw matrix of PF adheres to the friction disc, and the micro lump could be taken away by the counter disc. With the roughness of the friction surface increasing, the actual contact area between the friction surface and the friction disc increased. Due to the discontinuity of the adhesion point, the friction coefficient appears unstable. When graphite is added as lubricant, the graphite-containing transfer layer which is formatted in dynamic balance is formed on the friction surface. Therefore, the adhesive wear between PF and friction disc is reduced, and the friction stability is improved effectively.

Figure 4 shows the surface morphology of the Gr-free specimen at different speeds. When the sliding speed is $3.1 \mathrm{~m} / \mathrm{s}$, there are many grooves, spalling pits and compacted debris (Figure $4 \mathrm{a}$ ), which indicate that the main wear mechanism is abrasive wear $[10,49,50]$. For the PF and counterpart contact directly, strong plowing and asperity contact are responsible for the rough friction surface and high friction coefficient and wear rate (Figure 2). When the speed reaches $7.9 \mathrm{~m} / \mathrm{s}$, the friction surface is flat (Figure 4b). There are shallower grooves and less spalling pits. The continuous transfer films which are formed by abrasive particles covers the whole friction surface. Due to the engagement of PF and the counterpart, the large abrasive particles that fall off PF have a relative movement between the friction surfaces, resulting in a ball effect and a decrease in the friction coefficient (Figure $2 \mathrm{~b}$ ). The surface becomes rough when the sliding speed is up to $15.7 \mathrm{~m} / \mathrm{s}$ (Figure 4c). When the speed increases to $23.6 \mathrm{~m} / \mathrm{s}$, no grooves can be seen on the friction surface, and the compacted debris and a large number of spalling pits exist on the friction surface (Figure $4 \mathrm{~d}$ ). The roughness of the worn surface is increased a lot, which explains the sudden increase of the friction coefficient in Figure 2b. At high sliding speed, the shear force between the asperities of the PF and counterpart increases, and the transfer film on the friction surface becomes dense. The transfer films could break under the fatigue of repetitive contact and no contact and hence they peel off in some areas and become abrasive particles. For this process, the main wear mechanism is adhesive wear after the sliding speed of $7.9 \mathrm{~m} / \mathrm{s}$. When the speed reaches $31.4 \mathrm{~m} / \mathrm{s}$, the worn surface is covered by large amounts of transfer layer (Figure 4e). Because the transfer layer can reduce the frictional force between friction counter face, the friction coefficient decreases accordingly (Figure 2b). There is a large area of spalling pits on the friction surface when the speed reaches $47.1 \mathrm{~m} / \mathrm{s}$ (Figure $4 \mathrm{~d}$ ). The friction surface is rough (surface roughness $\left(\mathrm{R}_{\mathrm{a}}\right)$ is $3.96 \mu \mathrm{m}$ ), and the compacted debris shows on the actual contact areas. On one hand, under the high sliding speed condition, the temperature of the friction surface is high, accelerating the local aging of $\mathrm{PF}$, consequently reducing surface shear tolerance. On the other hand, the severe fatigue makes it difficult for the friction surface to accumulate continuous compacted transfer films, thereby the fragmentation occurs at the actual contact areas, causing high coefficient and wear rate.

It can be seen from Figure 4 that the re-transferred layer is formed on the surface of PF. At the initial stage of friction, the PF adhered on the steel surface, and when the stripped particles are stuck back to the original PF surface, this can be called re-adhesion. After repeated friction, fine particles are formed on the friction surface, and the final transfer is formed. In fact, the transfer layer comes from the re-adhesion from the steel disc, which can be called the re-transferred layer.

The 3-D morphologies of the friction surface of the Gr-PF friction composite 30Gr at two different sliding speeds are shown in Figure 5a,c. At the speed of $15.7 \mathrm{~m} / \mathrm{s}$, the friction surface has a high flatness barring several spalling pits on the friction surface (Figure 5a). The profile lines are average approximately $15.3 \mu \mathrm{m}$ in width and $1.4 \mu \mathrm{m}$ in depth (Figure 5b). When the speed reaches $47.1 \mathrm{~m} / \mathrm{s}$, because there is a lot of graphite to enhance the lubricating effect, the friction surface is flat (Figure 5c). Although there are some cracks and spalling pits on the friction surface, it is much smoother than that of the Gr-free specimen (Figure 4d). 

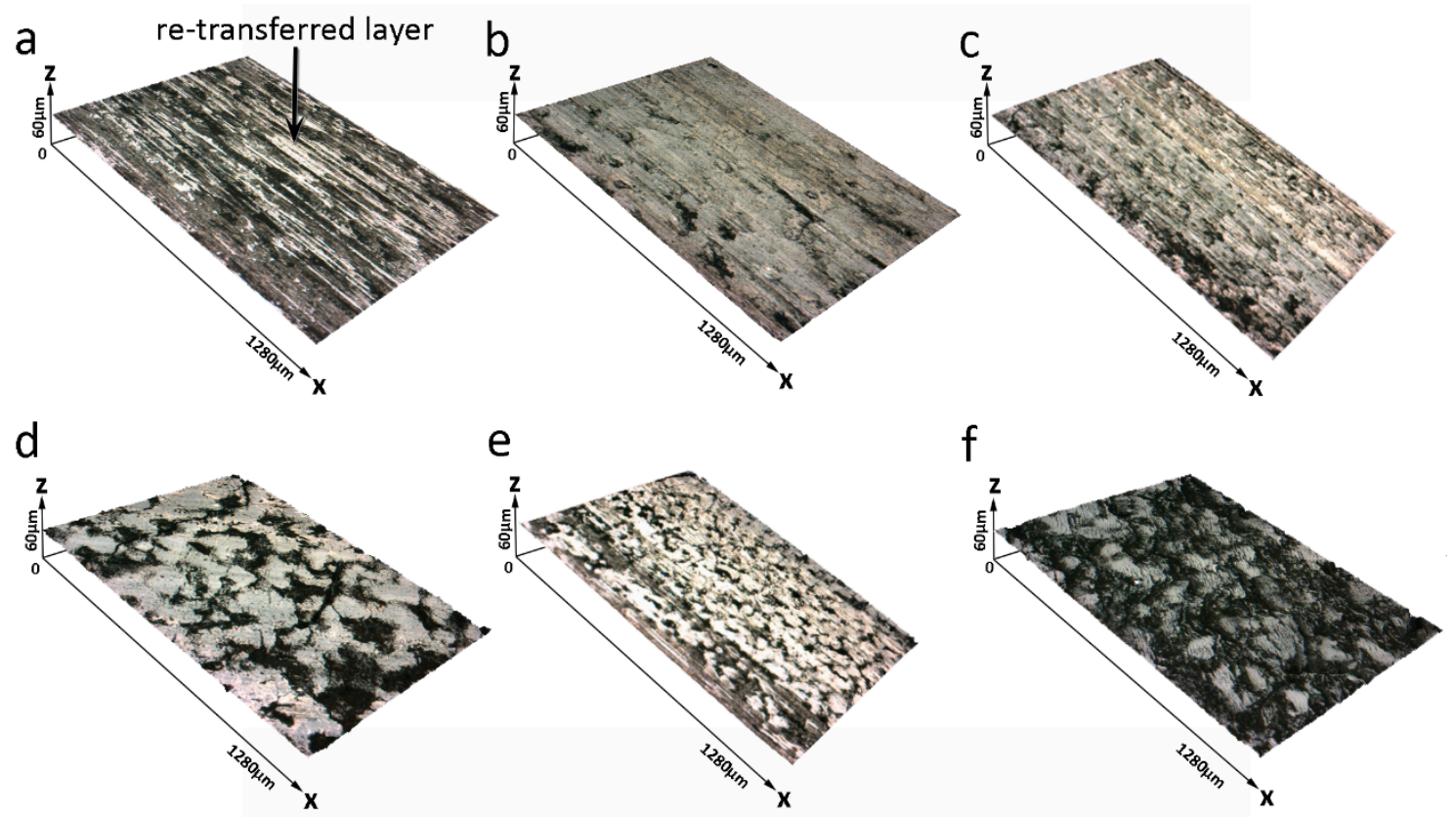

Figure 4. Three-dimensional (3-D) images of friction surface of the PF friction material at different friction speeds at $0.51 \mathrm{MPa}:$ (a) $3.1 \mathrm{~m} / \mathrm{s}$, (b) $7.9 \mathrm{~m} / \mathrm{s}$, (c) $15.7 \mathrm{~m} / \mathrm{s}$, (d) $23.6 \mathrm{~m} / \mathrm{s},(\mathbf{e}) 31.4 \mathrm{~m} / \mathrm{s}$, (f) $47.1 \mathrm{~m} / \mathrm{s}$.
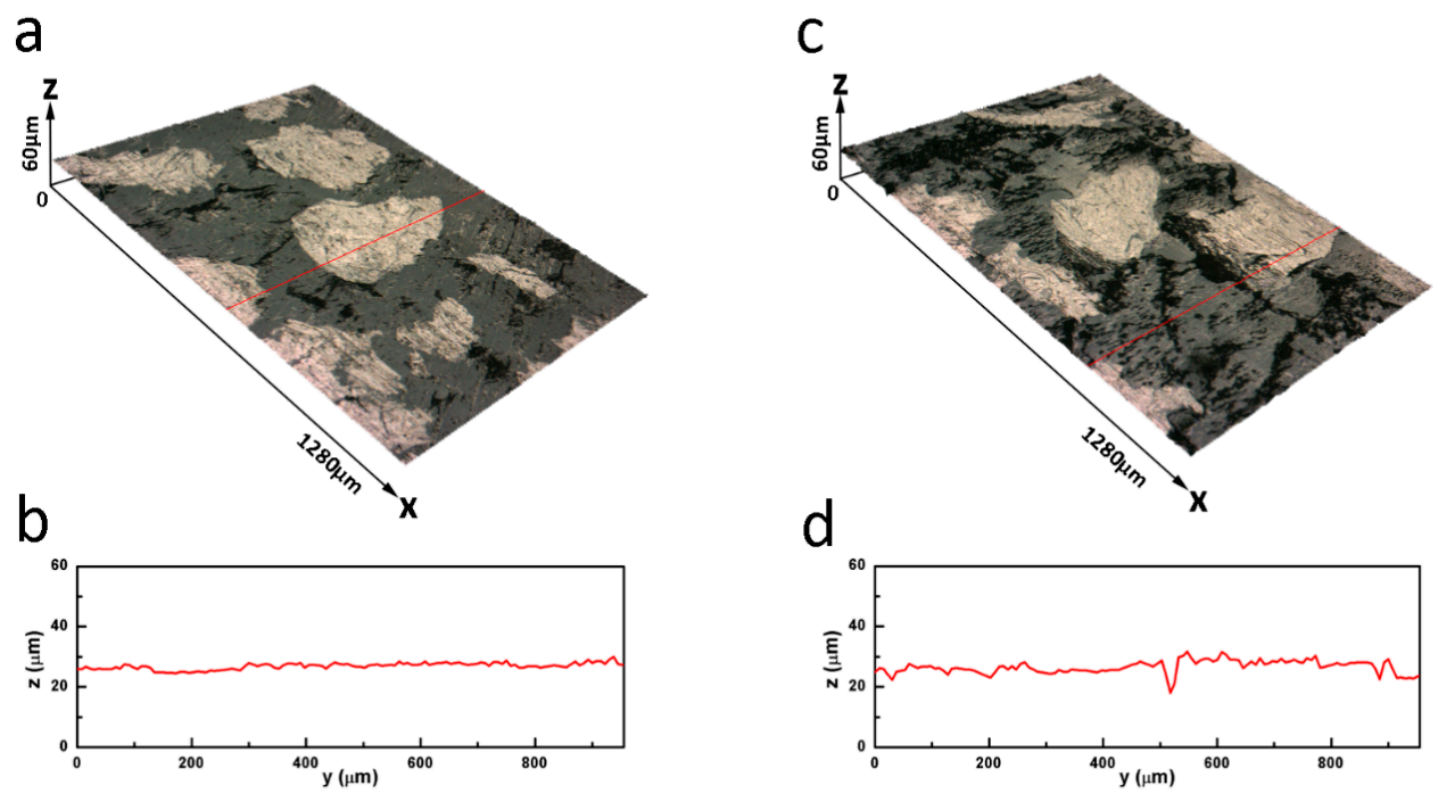

Figure 5. 3-D Images of friction surface of the Gr-PF friction composite with different speeds at $0.23 \mathrm{MPa}$ (a) $15.7 \mathrm{~m} / \mathrm{s}$, (b) profile lines of (a), (c) $47.1 \mathrm{~m} / \mathrm{s}$, (d) profile lines of (c).

The SEM images of the worn surfaces for the samples, as shown in Figure 6, can supply further information for the wear and friction mechanisms. For further information about the wear and friction mechanisms, the magnified SEM images of Figures $4 \mathrm{~d}$ and $5 \mathrm{c}$ are shown in Figure 6a,c. As shown in Figure 6a, part of the friction surface area is fractured and few cut-off lumpy pieces are observed on the worn surface. The friction surface is cracked and fractured, and then the lumpy pieces peel off with the high instantaneous asperity contact pressure and shearing force at the sliding speed of $47.1 \mathrm{~m} / \mathrm{s}$. Some lumpy pieces are smashed under the fatigue of repeated rolling and hence they become pulverized debris (see Figure 6b). For this process, the formation of fracture can be attributed to three aspects: degradation accelerated by friction heating, strong local shearing force and plastic 
deformation. The main wear mechanism is adhesive and it can be inferred that some of the pulverized debris are compacted on the unfractured friction surface and form continuous thin transfer film on local areas.
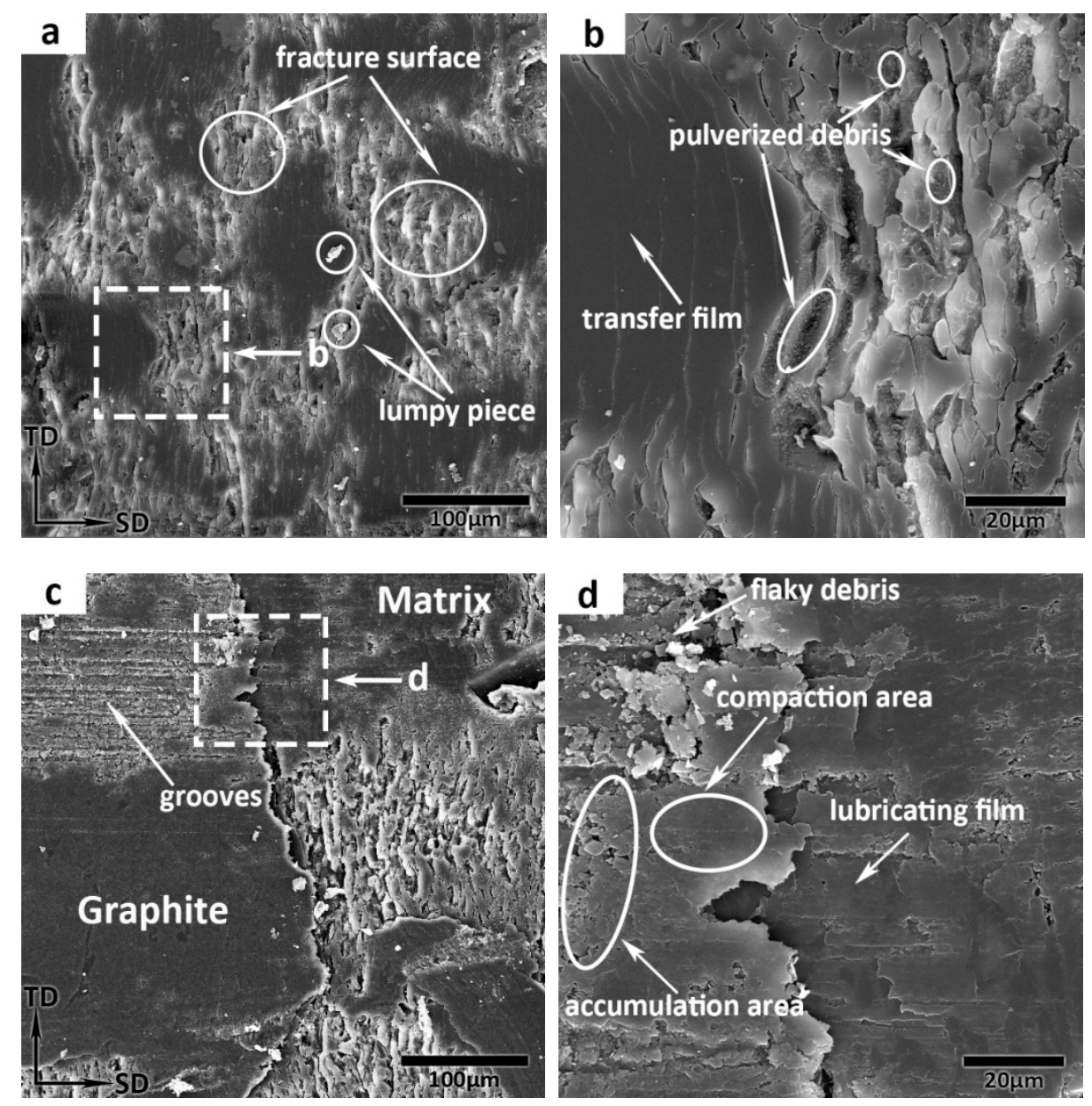

Figure 6. Scanning electron microscope (SEM) images of worn surface at $47.1 \mathrm{~m} / \mathrm{s}$ : (a) Gr-free PF friction composite, (b) the zoomed-in views of the rectangular area in (a), (c) Gr-PF friction composite, (d) the zoomed-in views of the rectangular area in (c).

After incorporating $30 \mathrm{vol} \%$ \% Gr into the friction composite, the SEM image of Figure 6c shows the Gr-PF boundary on the worn surface and displays milder damage. This result is consistent with the low wear rate and friction coefficient, and mainly attributed to the lubricant performance of Gr. Because the Gr and counterpart contact directly, the friction surface of $\mathrm{Gr}$ is scratched by asperities on the counterpart, and grooves and debris form. The magnified image of Figure $6 c$ shows more detail on the worn surface of the Gr-PF boundary and is characterized by flaky debris and lubricating film of Gr (Figure 6d). The above view is also consistent with the results reported by D. Puhan et al. [51]. It is inferred that the flaky debris can be dispersed along the sliding direction on the friction surface, then accumulates in contact plateaus and can be compacted, therefore, as the friction progresses, a continuous lubricating film is formed, and covers the PF worn surface. With the addition of Gr, the fatigue wear is the wear mechanism, and the peeling-off becomes a dominant wearing form of fatigue. Therefore, consistent with the test data shown in Figure 2, the $\mathrm{Gr}$ content composites get lower friction coefficient and wear rate than PF composite.

To express the friction mechanism of PF friction materials with the addition of Gr, comparing it with the Gr-free case, the formation mechanisms of the transfer film and lubricating film are listed below. For PF friction materials, their surfaces undergo a process of serious wear and tear, a small amount pulverized debris accumulates on low-lying place 
and forms a dense re-transfer film (Figure 7a). The rough worn surface which is formed by the severe wear could increase the roughness of the friction surface, so that the actual real contact area increases, and the friction coefficient and wear rate increases (Figure 2). For GrPF composite, flaky debris generates on the worn surface. During friction progress, most of the flaky debris are compacted forming smooth and dense lubricating film (Figure $7 \mathrm{~b}$ ). As can be seen from Figures 5 and $6 c, d$, the worn surface covered by Gr lubricating films is much flatter than the Gr-free PF friction material. The amount of fracture areas of $\mathrm{Gr}-\mathrm{PF}$ composite is lower than PF friction material. This suggests that the compacted $\mathrm{Gr}$ lubricating film decreases the actual contact area, which is conducive to decreasing the friction coefficient and wear rate.
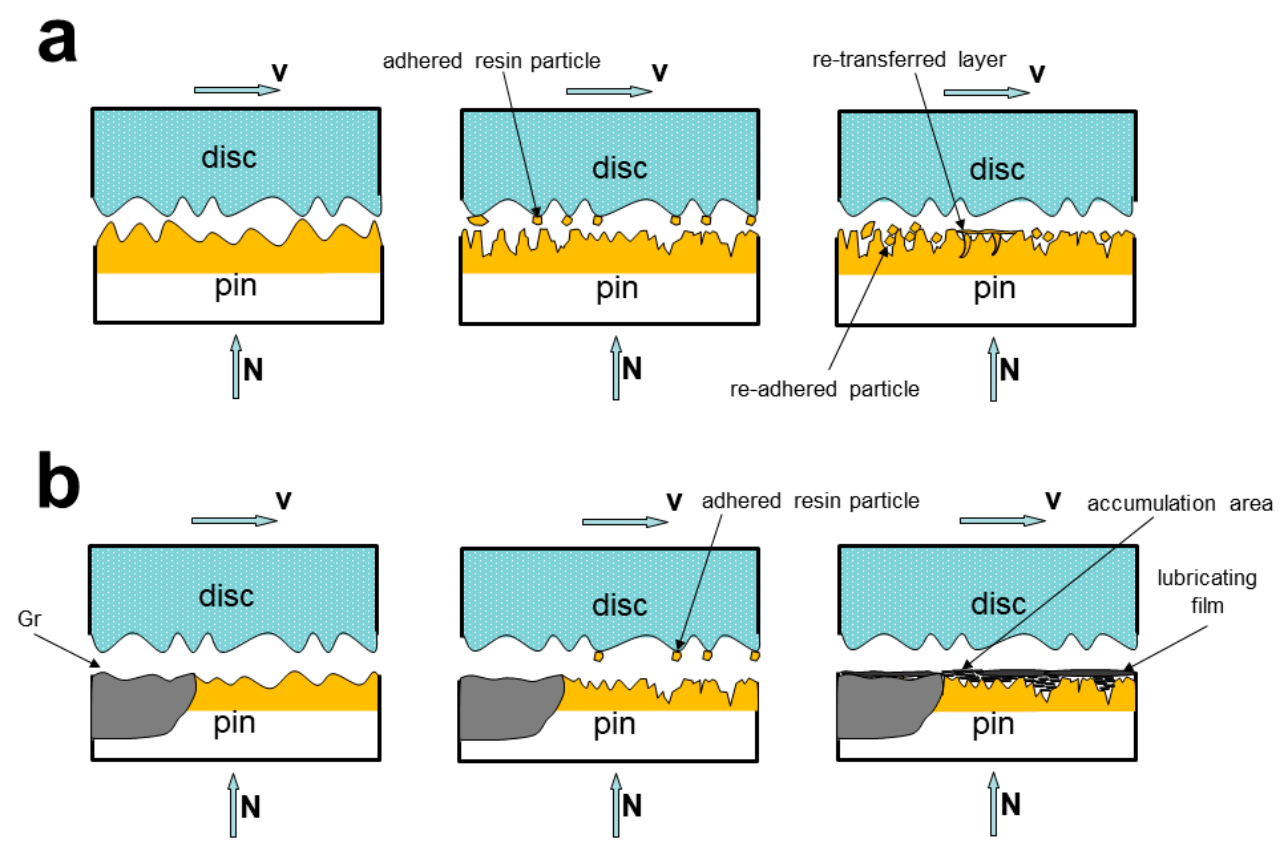

Figure 7. Schematic progress of compact lubricating/transfer film formation: (a) PF friction material without the addition of Gr; (b) PF friction material with the addition of Gr.

\section{Conclusions}

1. For the Gr-free PF material, there are many grooves and spalling pits on the friction surface at the sliding speed of $3.1 \mathrm{~m} / \mathrm{s}$, indicating that the main wear mechanism is abrasive wear. Therefore, the friction coefficient and wear rate are relatively high. When the speed exceeds $7.9 \mathrm{~m} / \mathrm{s}$, cracks and shallower grooves appear on the friction surface, and the dominant wear mechanisms change to adhesive wear.

2. The addition of Gr can effectively reduce the sensitivity of PF-based friction materials to sliding speeds, and thus enhance the stability of the friction coefficient. When the content of $\mathrm{Gr}$ is above $20 \mathrm{vol} \%$, the stability of the friction coefficient is relatively stable.

3. With the addition of $\mathrm{Gr}$, the friction coefficient and wear rate decrease effectively compared with the raw matrix of PF. The friction coefficient decreases with the increasing $\mathrm{Gr}$ content in the range of 10-30 vol.\%.

4. The dominant wear mechanism of PF friction material altered to fatigue wear (in the form of peeling-off) after the addition of Gr. A dense and continuous lubricating layer forms in the spalling pits where the flaky debris piles up and is compacted, which decreases the actual contact area between friction material and the steel disc; therefore, the friction coefficient and wear rate decrease and, consequently, the stability of friction coefficient under different sliding speed is enhanced. 
Author Contributions: Conceptualization, F.G. and E.Z.; methodology, E.Z. and X.H.; software, E.Z.; validation, X.H. and L.S.; formal analysis, R.F and L.S.; investigation, E.Z.; resources, F.G.; data curation, R.F.; writing-original draft preparation, E.Z.; writing-review and editing, Y.L.; visualization, Y.L.; supervision, R.F.; project administration, F.G.; funding acquisition, F.G. All authors have read and agreed to the published version of the manuscript.

Funding: This work was supported by the National Key Research and Development Plan (2016yfb0301403), and the National Key Research and Development Plan (2016yfb0301400).

Institutional Review Board Statement: The study was conducted according to the guidelines of the Declaration of Helsinki, and approved by the Institutional Review Board of Dalian Jiaotong University.

Informed Consent Statement: Informed consent was obtained from all subjects involved in the study.

Data Availability Statement: The data presented in this study are available on request from the corresponding author. The data are not publicly available.

Conflicts of Interest: The authors declare no conflict of interest.

\section{Appendix A}

For the friction coefficient data in Figure $2 b$ are average friction coefficient at each sliding speed, the on-line friction curves of each PF composite are shown in Figure A1 as follows.
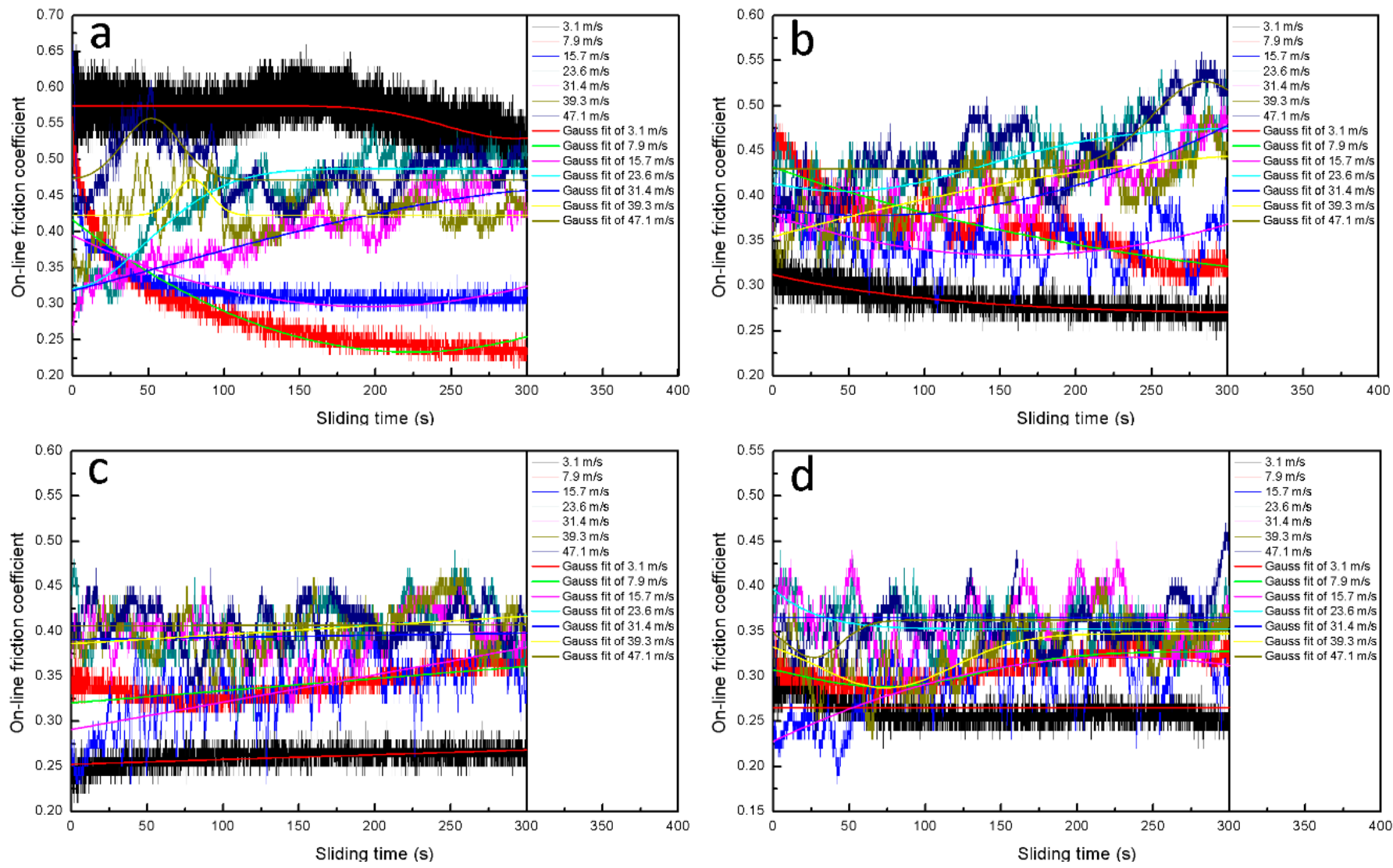

Figure A1. Cont. 


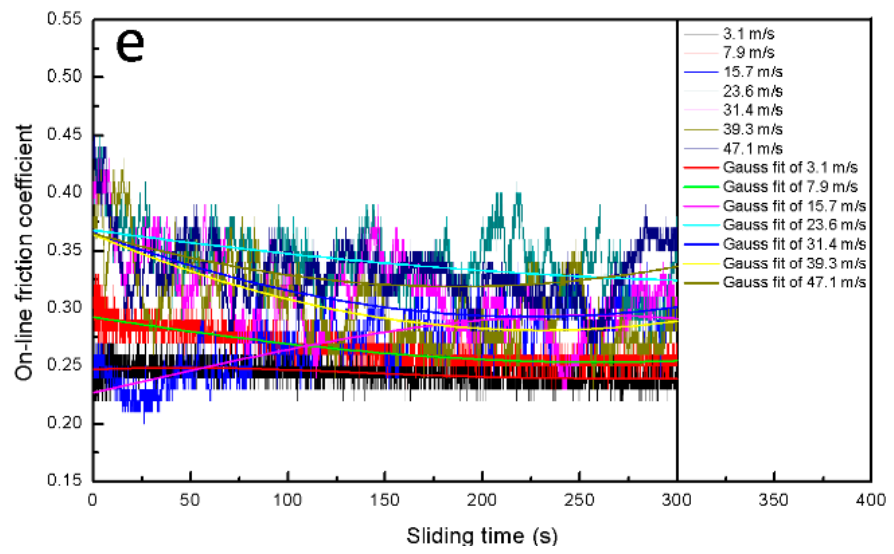

Figure A1. The on-line friction curves of each PF composite: (a) 0Gr; (b) 10Gr; (c) 20Gr; (d) 25Gr; (e) 30Gr.

\section{References}

1. Cao, H.; Qian, Z.; Zhang, L.; Xiao, J.; Zhou, K. Tribological behavior of cu matrix composites containing graphite and tungsten disulfide. Tribol. Trans. 2014, 57, 1037-1043. [CrossRef]

2. Cao, Z.; Xia, Y. Study on the preparation and tribological properties of fly ash as lubricant additive for steel/steel pair. Tribol. Lett. 2017, 65, 1-9. [CrossRef]

3. Conradi, M.; Kocijan, A.; Kosec, T.; Podgornik, B. Manipulation of TiO2 nanoparticle/polymer coatings wettability and friction in different environents. Materials 2020, 13, 1702. [CrossRef]

4. $\quad$ Lin, H.Y.; Cheng, H.Z.; Lee, K.J.; Wang, C.F.; Liu, Y.C.; Wang, Y.W. Effect of carbonaceous components on tribological properties of copper-free nao friction material. Materials 2020, 13, 1163. [CrossRef]

5. Barszcz, M.; Pashechko, M.; Dziedzic, K.; Józwik, J. Study on the self-organization of an Fe-Mn-C-B coating during friction with surface-active lubricant. Materials 2020, 13, 3025. [CrossRef]

6. Zhou, L.; Zhu, Z.; Yu, Z.; Zhang, C. Shear testing of the interfacial friction between an HDPE geomembrane and solid Waste. Materials 2020, 13, 1672. [CrossRef]

7. Krbata, M.; Eckert, M.; Bartosova, L.; Barenyi, I.; Majerik, J.; Mikuš, P.; Rendkova, P. Dry sliding friction of tool steels and their comparison of wear in contact with $\mathrm{ZrO} 2$ and X46Cr13. Matererials 2020, 13, 2359. [CrossRef] [PubMed]

8. Ozturk, B.; Ozturk, S.; Adigüzel, A.A. Effect of type and relative amount of solid lubricants and abrasives on the tribological properties of brake friction materials. Tribol. Trans. 2013, 56, 428-441. [CrossRef]

9. Peng, T.; Yan, Q.; Li, G.; Zhang, X.; Zefeng, W.; Jin, X. The Braking behaviors of cu-based metallic brake pad for high-speed train under different initial braking speed. Tribol. Lett. 2017, 65, 1-13. [CrossRef]

10. Su, L.; Fei, G.; Han, X.; Fu, R.; Zhang, E. Tribological behavior of copper-graphite powder third body on copper-based friction materials. Tribol. Lett. 2015, 60, 1-12. [CrossRef]

11. Xiong, X.; Chen, J.; Yao, P.; Li, S.; Huang, B. Friction and wear behaviors and mechanisms of Fe and $\mathrm{SiO} 2$ in $\mathrm{Cu}-\mathrm{based} \mathrm{P} / \mathrm{M}$ friction materials. Wear 2007, 262, 1182-1186. [CrossRef]

12. Dastan, D.; Banpurkar, A. Solution processable sol-gel derived titania gate dielectric for organic field effect transistors. J. Mater. Sci. Mater. Electron. 2017, 3851-3859. [CrossRef]

13. Altaf, F.; Batool, R.; Gill, R.; Rehman, Z.U.; Majeed, H.; Ahmad, A.; Shafiq, M.; Dastan, D.; Abbas, G.; Jacob, K. Synthesis and electrochemical investigations of ABPBI grafted montmorillonite based polymer electrolyte membranes for PEMFC applications. Renew. Energy 2021, 164, 709-728. [CrossRef]

14. Sun, L.; Liang, L.; Shi, Z.; Wang, H.; Xie, P.; Dastan, D.; Sun, K.; Fan, R. Optimizing strategy for the dielectric performance of topological-structured polymer nanocomposites by rationally tailoring the spatial distribution of nanofillers. Eng. Sci. 2020, 12, 95-105. [CrossRef]

15. Sun, L.; Shi, Z.; Liang, L.; Wei, S.; Wang, H.; Dastan, D.; Sun, K.; Fan, R. Layer-structured BaTiO3/P(VDF-HFP) composites with concurrently improved dielectric permittivity and breakdown strength toward capacitive energy-storage applications. J. Mater. Chem. C 2020, 8, 10257-10265. [CrossRef]

16. Sun, L.; Shi, Z.; Wang, H.; Zhang, K.; Dastan, D.; Sun, K.; Fan, R. Ultrahigh discharge efficiency and improved energy density in rationally designed bilayer polyetherimide-BaTiO3/P(VDF-HFP) composites. J. Mater. Chem. A 2020, 8, 5750-5757. [CrossRef]

17. Yang, J.; Zhu, X.; Wang, H.; Wang, X.; Shi, Z. Achieving excellent dielectric performance in polymer composites with ultralow filler loadings via constructing hollow-structured filler frameworks. Compos. Part A Appl. Sci. Manuf. 2020, 131, 105814. [CrossRef]

18. Zhang, W.; Zhu, X.; Liang, L.; Yin, P.; Xie, T.; Dastan, D.; Sun, K.; Fan, R.; Shi, Z. significantly enhanced dielectric permittivity and low loss in epoxy composites incorporating 3D W-WO 3 /BaTiO 3 foams. J. Mater. Sci. 2021, 56, 1-12. [CrossRef] 
19. Zhu, X.; Yang, J.; Dastan, D.; Garmestani, H.; Shi, Z. fabrication of core-shell structured Ni@BaTiO3 scaffolds for polymer composites with ultrahigh dielectric constant and low loss. Compos. Part A Appl. Sci. Manuf. 2019, 125, 105521. [CrossRef]

20. Abbasi, S.; Wahlström, J.; Olander, L.; Larsson, C.; Olofsson, U.; Sellgren, U. A study of airborne wear particles generated from organic railway brake pads and brake discs. Wear 2011, 273, 93-99. [CrossRef]

21. Chan, D.S.E.A.; Stachowiak, G.W. Review of automotive brake friction materials. Proc. Inst. Mech. Eng. Part D 2004, $218,953-966$. [CrossRef]

22. Gurunath, P.V.; Bijwe, J. Friction and wear studies on brake-pad materials based on newly developed resin. Wear 2007, 263, 1212-1219. [CrossRef]

23. Kim, S.J.; Jang, H. Friction and wear of friction materials containing two different phenolic resins reinforced with aramid pulp. Tribol. Int. 2000, 33, 477-484. [CrossRef]

24. Kuroe, M.; Tsunoda, T.; Kawano, Y.; Takahashi, A. Application of lignin-modified phenolic resins to brake friction material. J. Appl. Polym. Sci. 2012, 129, 310-315. [CrossRef]

25. Luo, Y.; Yang, Z. Effect of different-condition parameters on frictional properties of non-asbestos phenolic resin-based friction material. Adv. Mech. Eng. 2017, 9, 168781401771011. [CrossRef]

26. Ma, B.J.; Zhu, J. Wear mechanisms of kevlar pulp reinforced phenolic resin friction materials. Tribology 2001, 21, $205-209$.

27. Takaku, K.; Kuriyama, T.; Narisawa, I. tribology of phenolic-resin composites III. Tribology of phenolic-resin based glass fiber composites. Seikei Kakou 2009, 6, 582-588. [CrossRef]

28. Archard, J.F. Contact and rubbing of flat surfaces. J. Appl. Phys. 1953, 24, 981-988. [CrossRef]

29. Betancourt, S.; Cruz, J.; Toro, A. Friction and wear in sliding contact of cast iron against phenolic resin composites reinforced with carbonaceous fibres from plantain fibre bundles. Lubr. Sci. 2012, 25, 163-172. [CrossRef]

30. Eriksson, M.; Jacobson, S. Tribological surfaces of organic brake pads. Tribol. Int. 2000, 33, 817-827. [CrossRef]

31. Kumar, S.S.; Kanagaraj, G. Investigation on mechanical and tribological behaviors of pa6 and graphite-reinforced PA6 polymer composites. Arab. J. Sci. Eng. 2016, 41,1-11.

32. Aderikha, V.N.; Krasnov, A.P.; Naumkin, A.V.; Shapovalov, V.A. Effects of ultrasound treatment of expanded graphite (EG) on the sliding friction, wear resistance, and related properties of PTFE-based composites containing EG. Wear 2017, 63-71. [CrossRef]

33. Aranganathan, N.; Bijwe, J. Comparative performance evaluation of nao friction materials containing natural graphite and thermo-graphite. Wear 2016, 358, 17-22. [CrossRef]

34. Ghosh, P.; Ghosh, D.; Chaki, T.K.; Khastgir, D. NBR powder modified phenolic resin composite: Influence of graphite on tribological and thermal properties. Tribol. Trans. 2016, 60, 1-37. [CrossRef]

35. Liu, X.; Wu, Y.; Yu, Z. Tribological properties of organic functionalized ZrB2-Al2O3/Epoxy Composites. Tribol. Lett. 2017, 65, 1-9. [CrossRef]

36. Padenko, E.; Van Rooyen, L.J.; Karger-Kocsis, J. Transfer Film Formation in PTFE/Oxyfluorinated Graphene Nanocomposites During Dry Sliding. Tribol. Lett. 2017, 65, 36. [CrossRef]

37. Rhee, S.K. Friction properties of a phenolic resin filled with iron and graphite-Sensitivity to load, speed and temperature. Wear 1974, 28, 277-281. [CrossRef]

38. Subramanian, C.; Asaithambi, P.; Kishore. Friction and wear of epoxy resin containing graphite. J. Reinf. Plast. Compos. 1986, 5, 200-208. [CrossRef]

39. Ya-Fei, H.U.; Wang, Q.L.; Liu, Q.; Xiong, J.J. Research on forming rule of lubricant film and friction-wearing of graphite composite materials. J. China Univ. Min. Technol. 2010, 3, 223-226.

40. Zhu, Z.; Bai, S.; Wu, J.; Xu, L.; Li, T.; Ren, Y.; Liu, C. Friction and wear behavior of resin/graphite composite under dry sliding. J. Mater. Sci. Technol. 2015, 31, 325-330. [CrossRef]

41. Min, H.C.; Ju, J.; Kim, S.J.; Jang, H. Tribological properties of solid lubricants (graphite, Sb2S3, MoS2) for automotive brake friction materials. Wear 2006, 260, 855-860. [CrossRef]

42. Alajmi, M.; Shalwan, A. Correlation between mechanical properties with specific wear rate and the coefficient of friction of graphite/epoxy composites. Materials 2015, 8, 4162-4175. [CrossRef] [PubMed]

43. Kumar, M.; Bijwe, J. Composite friction materials based on metallic fillers: Sensitivity of $\mu$ to operating variables. Tribol. Int. 2011, 44, 106-113. [CrossRef]

44. Cui, G.; Niu, M.; Zhu, S.; Yang, J.; Bi, Q. Dry-Sliding tribological properties of bronze-graphite composites. Tribol. Lett. 2012, 48, 111-122. [CrossRef]

45. Yi, G.; Yan, F. Mechanical and tribological properties of phenolic resin-based friction composites filled with several inorganic fillers. Wear 2007, 262, 121-129. [CrossRef]

46. Liu, L.; Sheng, Y.; Liu, M.; Dienwiebel, M.; Zhang, Z.; Dastan, D. Formation of the third bodies of steel sliding against brass under lubricated conditions. Tribol. Int. 2019, 140, 105727. [CrossRef]

47. Liu, M.; Li, C.; Liu, L.; Ye, Y.; Dastan, D.; Garmestani, H. Inhibition of stress corrosion cracking in 304 stainless steel through titanium ion implantation. Mater. Sci. Technol. 2019, 36, 284-292. [CrossRef]

48. Guang-Lei, T.; Dan, T.; Davoud, D.; Azadeh, J.; José, P.B.S.; Xi-Tao, Y. Effect of heat treatment on electrical and surface properties of tungsten oxide thin films grown by HFCVD technique. Mater. Sci. Semicond. Proc. 2021, 122. [CrossRef]

49. Gao, F.; Su-Qiang, D.U.; Rong, F.U.; Song, B.Y. Effects of graphite content on performance of copper-based friction materials. Min. Metall. Eng. 2005, 4. [CrossRef] 
50. Su, L.; Gao, F.; Han, X.; Chen, J. Effect of copper powder third body on tribological property of copper-based friction materials. Tribol. Int. 2015, 90, 420-425. [CrossRef]

51. Puhan, D.; Bijwe, J.; Parida, T.; Trivedi, P. Investigations on performance properties of nano-micro composites based on polyetherketone, short carbon fibers and hexa-boron nitride. Sci. Adv. Mater. 2015, 7, 1002-1011. [CrossRef] 